
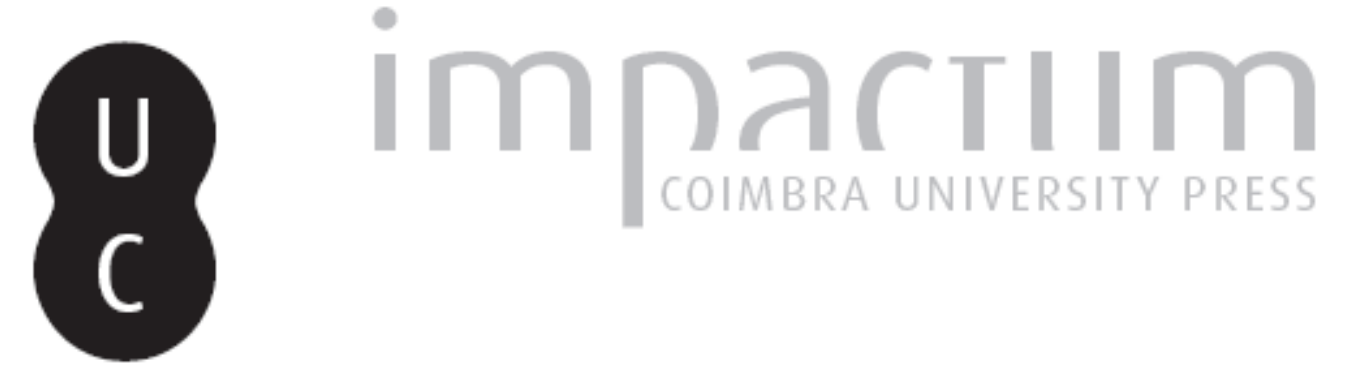

\title{
A cobertura televisiva da corrupção em anos eleitorais: uma análise do enquadramento do caso Petrolão nos noticiários de emissoras pública e comercial
}

Autor(es): $\quad$ Coutinho, lluska; Oliveira Filho, José Tarciso

Publicado por: Imprensa da Universidade de Coimbra

URL persistente:

URI:http://hdl.handle.net/10316.2/36969

DOI:

DOI:http://dx.doi.org/10.14195/2183-5462_26_9

Accessed : $\quad$ 26-Apr-2023 06:50:35

A navegação consulta e descarregamento dos títulos inseridos nas Bibliotecas Digitais UC Digitalis, UC Pombalina e UC Impactum, pressupõem a aceitação plena e sem reservas dos Termos e Condições de Uso destas Bibliotecas Digitais, disponíveis em https://digitalis.uc.pt/pt-pt/termos.

Conforme exposto nos referidos Termos e Condições de Uso, o descarregamento de títulos de acesso restrito requer uma licença válida de autorização devendo o utilizador aceder ao(s) documento(s) a partir de um endereço de IP da instituição detentora da supramencionada licença.

Ao utilizador é apenas permitido o descarregamento para uso pessoal, pelo que o emprego do(s) título(s) descarregado(s) para outro fim, designadamente comercial, carece de autorização do respetivo autor ou editor da obra.

Na medida em que todas as obras da UC Digitalis se encontram protegidas pelo Código do Direito de Autor e Direitos Conexos e demais legislação aplicável, toda a cópia, parcial ou total, deste documento, nos casos em que é legalmente admitida, deverá conter ou fazer-se acompanhar por este aviso.

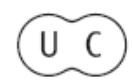




\section{Media Jornalismo}

\section{CORRUPÇÃO POLÍTICA, MEDIA E DEMOCRACIA}




\section{A COBERTURA TELEVISIVA DA CORRUPÇÃO EM ANOS ELEITORAIS: UMA ANÁLISE DO ENQUADRAMENTO DO CASO PETROLÃO NOS \\ NOTICIÁRIOS DE EMISSORAS PÚBLICA E COMERCIAL. \\ THE TELEVISION COVERAGE OF CORRUPTION IN ELECTION YEARS: AN ANALYSIS OF THE BACKGROUND OF THE CASE PETROLÃO IN THE NEWS PUBLIC AND COMMERCIAL BROADCASTERS.}

\section{ILUSKA COUTINHO E JOSÉ TARCISO OLIVEIRA FILHO}

ILUSKA.COUTINHO@UFJL.EDU.ER | JTARCISIOFILH0@GMAIL.COM

\section{Resumo}

Meio de acesso à informação de significativa parcela da população brasileira, a televisão ofereceria, por meio de seus telejornais, formas de acompanhamento do mundo e da política aos telespetadores, cidadãos. Se ao jornalismo caberia o papel de atuar como monitor independente, a proposta é analisar em que medida a cobertura televisiva da corrupção estaria estruturada sob a dimensão do escândalo, em anos eleitorais. A reflexão toma como objeto de análise a veiculação do caso Petrolão na mídia brasileira durante o segundo turno das eleições presidenciais de 2014. A cobertura midiática do escândalo, que começou no primeiro semestre daquele ano e envolveu a corrupção na petrolífera estatal Petrobrás, teve a repercussão ampliada diante da divulgação dos depoimentos do ex-diretor de abastecimento da empresa, Paulo Roberto Costa, e doleiro Alberto Youssef duas semanas antes da votação do segundo turno. A análise da produção audiovisual veiculada tem como procedimento metodológico a análise de conteúdo, associada à dramaturgia do telejornalismo, utilizadas de modo a evidenciar as diferenças e semelhanças qualitativas e quantitativas nas coberturas no noticiário de uma emissora pública, o Repórter Brasil, da TV Brasil, e no de uma TV Comercial, o Jornal Nacional, da Rede Globo.

Palavras-chave

Petrobrás, Repórter Brasil, Jornal Nacional, Eleições, Cobertura Midiática.

Abstract

This article shows the results of research on the case Petrolão, displayed by the Brazilian media during the presidential elections of 2014. The scandal, which began in the first half and involved corruption in state oil company Petrobrás, received considerable attention after the release of testimony from a former director of the company and an accomplice - two weeks before the polling day of the second round of elections. The research aims to investigate the differences and similarities about the coverage between television news of a public broadcaster, the Reporter Brazil, from the TV Brazil, and the Jornal Nacional, from a commercial TV (Rede Globo).

Petrobrás, Repórter Brasil, Jornal Nacional, Brazilian Elections, Media Coverage. 


\author{
A COBERTURA TELEVISIVA DA CORRUPÇÃO EM ANOS \\ ELEITORAIS: UMA ANÁLISE DO ENQUADRAMENTO DO CASO \\ PETROLÃO NOS NOTICIÁRIOS DE EMISSORAS PÚBLICA E \\ COMERCIAL.
}

THE TELEVISION COVERAGE OF CORRUPTION IN ELECTION

YEARS: AN ANALYSIS OF THE BACKGROUND OF THE CASE

PETROLÃO IN THE NEWS PUBLIC AND COMMERCIAL

BROADCASTERS.

ILUSKA COUTINHO | UNIVERSIDADE FEDERAL DE JUIZ DE FORA

ILUSKA.COUTINHO@UFJL.EDU.ER

JOSÉ TARCÍSIO OLIVEIRA FILHO | UNIVERSIDADE FEDERAL DE JUIZ DE FORA

JTARCISIOFILHO@GMAIL.COM

InTRODUÇÃo

Segundo eletrodoméstico mais presente nos lares do país, a televisão exerce um papel central também nos processos de (re)conhecimento e acompanhamento das informações políticas no Brasil. E considerando uma das promessas fundamentais do jornalismo a de atuar como um monitor independente, fiel à enfoque de atuar como um poder fiscalizador dos demais, assume-se como perspetiva de investigação o papel desempenhado pelos telejornais veiculados em horário nobre em duas emissoras de televisão na cobertura de um caso de corrupção, o chamado Petrolão, desencadeado em 2014, ano de eleições presidenciais brasileiras.

Constituídos como a praça pública na qual o Brasil (é) ditado, como anunciam os títulos de dois livros publicados pela Rede de Pesquisadores de Telejornalismo (Telejor), os telejornais brasileiros seriam um lugar de referência, para Alfredo Vizeu e João Carlos Correia (2008). A partir das contribuições, sobretudo, de Paulo Freire, os autores avaliam as funções dos noticiários de televisão na contemporaneidade, postulando uma ampliação do lugar de segurança que antes ocupavam, para sua conversão em lugar de referência, de construção do real pelos telespectadores.

Na cobertura das informações sobre o poder, no que refere-se às relações entre jornalismo e política no Brasil, os telejornais atuariam como sistemas peritos segundo Ananias José de Freitas: "aparecer na mídia é condição essencial para transitar na esfera política na atualidade" (2000). 0 autor defendeu então que a cobertura da política no telejornalismo reforçava o esvaziamento desta, valorizava as dimensões da encenação e da estetização e conotava um sentido geral negativo para esse campo.

Iluska Coutinho (2008) acrescenta ainda que por meio de suas coberturas, de sua dramaturgia e ritmos os telejornais também exerceriam um papel político ordenador em sociedades como a brasileira. Segundo a autora, por meio de sua lógica de produção, de suas narrativas, o telejornalismo mostraria o mundo por meio de sua janela, enquadramentos que envolvem recortes, inclusive político, especialmente 
em anos eleitorais. É nesse sentido que ganha relevância refletir sobre a cobertura da corrupção nos moldes propostos nesse artigo.

Autores como Teles, Fraiha \& Lopes (2014) consideram que a demanda por informações na esfera política é atendida prioritariamente pela mídia, televisiva em particular. Os telejornais seriam uma das principais formas dos cidadãos saberem sobre a corrupção cometida por, ou envolvendo agentes públicos. Ao fazer referência à pesquisa que analisou a percepção dos eleitores acerca da corrupção política nas eleições municipais de Belo Horizonte, em 2012, eles afirmam que: "A televisão parece ser o principal divulgador dos casos de corrupção: 93\% do eleitorado soube de casos de corrupção através de informações veiculadas pela televisão" (Teles, Fraiha \& Lopes: 2014: 304).

É a partir desse quadro teórico inicial, e da relevância da cobertura da corrupção política nos telejornais brasileiros, que propõe-se analisar a cobertura das denúncias sobre a corrupção envolvendo a Petrobrás, empresa brasileira de capital misto voltada para a exploração de petróleo e seus derivados, em dois telejornais noturnos veiculados nacionalmente: Jornal Nacional (TV Globo) e Repórter Brasil (TV Brasil). Essas denúncias, e sua cobertura, obtiveram destaque midiático ao longo do ano de 2014 e demonstraram tratamentos distintos entre emissoras brasileiras que apresentam diferentes modelos de gestão e financiamento. Na mídia comercial o assunto se fez presente nos alinhamentos (scripts) dos telejornais de forma contínua.

Entretanto, observou-se a necessidade de avaliar como essa cobertura seria realizada pela TV Pública Brasileira - já que a maior parte das ações da petrolífera é proveniente do Governo Federal, responsável pelo repasse de parte considerável dos recursos para a emissora. Também há de se notar que a parte mais intensa das investigações, como o depoimento de ex-diretor do setor de abastecimento da companhia, Paulo Roberto Costa, e de um dos membros envolvidos no esquema, 0 doleiro Alberto Youssef, aconteceu justamente no intervalo compreendido entre 0 primeiro e o segundo turno das eleições para presidente.

Os resultados apresentados neste artigo são referentes a uma pesquisa que começou em março de 2014, através da análise de um dos primeiros casos de corrupção envolvendo a Petrobrás - 0 da refinaria de Pasadena, cujos dados foram apresentados no Congresso Latino-Americano dos Investigadores da Comunicação (ALAIC), realizado no Peru. 0 trabalho consistiu na análise da cobertura do telejornal mais visto do país, o Jornal Nacional, veiculado pela TV Globo, emissora comercial, e do Repórter Brasil segunda edição, da TV Brasil, emissora pública.

Para compreender o tratamento dado por esses dois telejornais à divulgação das notícias envolvendo a Petrobrás, consideramos importante retomar as informações levantadas nesta primeira pesquisa, e relacioná-las com a nova análise realizada às vésperas das eleições, um dos momentos considerados mais delicados do ano eleitoral brasileiro. Realiza-se assim breve retrospectiva do Caso Petrolão-como é chamado esse esquema de corrupção na mídia comercial brasileira, assim como caracterizar o Repórter Brasil e o Jornal Nacional quanto às suas origens e propostas.

\section{Petrolão: Corrupção, polêmica e ênfase midiática.}

Escândalos, rombos, corrupção foram apenas algumas das palavras repetidas dia após dia pela grande mídia brasileira ao longo de 2014 em referência a 
maior empresa petrolífera do Brasil. 0 primeiro caso de maior repercussão foi em março, envolvendo a compra da refinaria da cidade de Pasadena, nos Estados Unidos. A transação foi divulgada por parte da imprensa nacional e por políticos da oposição, como um dos piores negócios da história da Estatal desde sua fundação, em 1953.

Segundo informações divulgadas pelo Jornal Nacional, em 2005 a empresa Belga Astra Oil comprou Pasadena por US\$126 milhões. Um ano depois, a Petrobrás adquiriu metade da empresa por US\$ 416 milhões. 0 valor chamou a atenção por ser bem maior do que os belgas haviam pago por toda a refinaria. A justificativa, na época, é de que haviam sido realizados investimentos que agregaram valor ao negócio. Porém, os gastos foram ainda maiores. Em 2008 a Astra Oil, alegando conflitos de gestão com a Petrobrás, obrigou a estatal brasileira a comprar o restante da refinaria - o que seria permitido devido a uma cláusula chamada de "put option" no contrato. Depois de acionar a justiça americana e perder a causa, a Petrobrás teve que desembolsar US\$ 820 milhões pela outra metade de Pasadena, acumulando um gasto total de US $\$ 1,236$ bilhões, um valor considerado excessivo pelos economistas.

Os principais telejornais de emissoras comerciais brasileiras intensificaram a cobertura no dia 19 de março, quando a presidente Dilma Rousseff divulgou um comunicado oficial na qual afirmava desconhecer cláusulas importantes do contrato de compra entre a Petrobrás e a Belga Oil. Durante nove dias, Oliveira Filho e Coutinho (2014), do Laboratório de Jornalismo e Narrativas Audiovisuais da Universidade Federal de Juiz de Fora, analisaram a repercussão do caso no Jornal Nacional e no Repórter Brasil $2^{a}$ Edição.

A análise de conteúdo apontou um contraste entre a repercussão excessiva das denúncias e o silêncio. Enquanto o Jornal Nacional investiu no caso de forma sistemática, dedicando $54 \mathrm{~m} 31 \mathrm{~s}$ de cobertura nos dias pesquisados, o Repórter Brasil abordou o assunto em apenas 3m20s no mesmo período. 0 telejornal da TV comercial repercutiu o caso para além de Pasadena, e intensificou a polêmica envolvendo a Petrobrás através de outras obras da Estatal que também haviam indícios de irregularidades, como 0 atraso das obras na refinaria de Pernambuco e do Complexo Petroquímico do Rio de Janeiro. Em algumas reportagens, a oposição obteve maior espaço, como na edição em que foi divulgado o comunicado oficial da presidência da república. Logo após a veiculação do conteúdo do documento foi inserida uma sonora' do senador Aécio Neves (PSDB), então pré-candidato às eleições presidenciais, com 23 segundos de duração. Nela, 0 adversário político do governo fez críticas à presidente, que na época em que o contrato foi fechado, era Ministra da Casa Civil. Depois, com sete segundos a menos, o líder do governo no Senado, Eduardo Braga (PMDB), defendeu as condutas da atual chefe do executivo (Oliveira Filho e Coutinho: 2014:10).

Com uma ênfase maior no assunto, o Jornal Nacional também apresentou uma cobertura mais diversificada em termos dos formatos jornalísticos utilizados, como

1 Sonoras são as entrevistas gravadas e que, geralmente, são inseridas numa reportagem. Alguns telejornais utilizam também a sonora de forma isolada, quando é veiculada fora de uma matéria. 
reportagens, notas secas ${ }^{2}$, artes ${ }^{3}$ e notas cobertas ${ }^{4}$. Imagens gravadas nos Estados Unidos também foram exibidas com frequência e com uma logo colorida no canto da tela com o símbolo da TV Globo, que remetia a exclusividade. Com condições financeiras mais enxutas, a TV Brasil se mostrou excessivamente cautelosa na abordagem do tema. Porém, foi inevitável questionar o silêncio diante do caso.

É evidente que a TV Brasil não possui tantos recursos quanto a estrutura comercial para enviar um correspondente ou cinegrafista para Pasadena, como fez o Jornal Nacional. Porém, as discussões realizadas no Congresso eram cobertura de fácil acesso para a emissora pública, na medida em que ocorriam mesma cidade onde o telejornal é ancorado - Brasília. É importante destacar também que alguma das notas, como a exibida no dia 19/03, quando começou a série de reportagens pelo JN, foram dedicadas exc/usivamente para dar voz a defesa do governo federal. Nenhum depoimento de parlamentares da oposição, que protocolaram o pedido da $\mathrm{CPI}$, foi inserido. Já o Ministro da Justiça, durante 44 segundos, encontrou espaço para criticar a conduta de deputados e senadores do congresso que fizeram o pedido da Comissão Parlamentar. Atitudes como essa, mostram o aparente "medo" de uma emissora - que tem a maior parte das verbas oriundas do governo - em dar destaque a assuntos polêmicos, que envolvem a presidência (Oliveira Filho e Coutinho: 2014: 12).

0 comportamento das duas emissoras no caso Pasadena representou o contraste existente entre as TVs Comerciais e Públicas brasileiras. Num aspecto prático, entre aquelas que dependem do dinheiro privado, e por isso precisam fomentar assuntos potenciais geradores de audiência, e emissoras que vivem às custas dos recursos repassados pelo governo, e portanto, aparentam encarar as denúncias envolvendo o poder executivo com maior cautela, e muitas vezes, sem profundidade. Essas características foram frequentemente visualizadas durante 0 ano de 2014. Entretanto, a realização das eleições presidenciais demonstrou a necessidade de avaliar como a mídia iria conduzir as denúncias diante do embate entre as candidaturas da oposição e do governo que tentava a reeleição. Um agravante foi a divulgação do depoimento do ex-diretor de abastecimento da Petrobrás, Paulo Roberto Costa e do doleiro Alberto Youssef, pela Justiça do Estado do Paraná, em pleno segundo turno eleitoral. Os réus revelaram com detalhes como funcionava os esquemas de corrupção envolvendo a Petrobrás.

Toda a investigação pertence à Operação Lava Jato, da Polícia Federal Brasileira, que identificou dirigentes da Petrolífera envolvidos com o pagamento de propina a políticos e grandes empreiteiras. As propinas eram cobradas através do recolhi-

2 Nota seca é o texto lido pelo apresentador para noticiar algum assunto. 0 termo "seca" é utilizado para demonstrar que a informação é transmitida apenas pela voz do apresentador, sem o uso de imagens, artes ou qualquer outro recurso.

3 As artes são os recursos gráficos utilizados pelos telejornais para explicar com maior didatismo 0 assunto. Podem ser mapas interativos, infográficos ou esquemas feitos por uma equipe composta geralmente por profissionais de designers gráficos que trabalham sob demanda da ilha de edição.

4 A nota coberta trata-se de uma nota seca, lida pelo apresentador, entretanto acompanhada com imagens. Geralmente é utilizada quando o assunto não tem o destaque para virar uma reportagem completa ou não há tempo suficiente para editar a reportagem. A nota coberta pode ser produzida com imagens gravadas por um cinegrafista profissional ou mesmo por fotos/vídeos enviados por telespectadores. 
mento de $3 \%$ no valor dos contratos da Estatal. Dezenas de pessoas, entre políticos e empresários, estariam envolvidos, consolidando todo o esquema como Petrolão pela mídia comercial brasileira - em referência ao Mensalão $0^{5}$, um outro escândalo de corrupção envolvendo o Partido dos Trabalhadores (PT) e o Governo Federal. Considerando a repercussão e o momento político daquela ocasião, foi realizada uma nova pesquisa para visualizar como os telejornais conduziram essa turbulência na política brasileira. Porém, antes, consideramos importante caracterizar as diferenças entre as origens e propostas entre os dois telejornais considerados objetos de estudo deste trabalho.

\section{Jornal Nacional e Repórter Brasil}

A primeira edição do Repórter Brasil foi veiculada no dia 3 de dezembro de 2007, um dia depois do início das transmissões da TV Brasil pela Empresa Brasil de Comunicação $(E B C)^{6}$. Veiculado de segunda a sábado às 21 horas, com uma hora de duração, incluindo intervalos, o telejornal tem seu estúdio em Brasília, mas conta com material de parceiras de todo o país.

Por ser produzido e veiculado em uma TV Pública, considera-se que o dinheiro que custeia o programa é proveniente do cidadão e, portanto, o conteúdo da emissora não deveria ser submisso aos interesses do governo federal. Essa questão da independência é reafirmada por vários autores que se dedicam a caracterizar a TV Pública na América Latina, como Barbero (2002) e Fernández (2002).

A autonomia para definir a produção, programação e veiculação do conteúdo também constitui um dos princípios descritos no Manual de Jornalismo da EBC. Nele, a base dos princípios é atrelada a construção da cidadania e da democracia, garantindo a expressão da diversidade social, cultural, regional e étnica. Há também ênfase na subordinação do trabalho da EBC aos interesses da sociedade (Manual de Jornalismo da EBC, 2013: 10). Em suma, o documento considera, entre os objetivos, os seguintes tópicos:

\section{Quadro 1: Princípios editoriais da Empresa Brasil de Comunicação}

\begin{tabular}{|l|l|}
\hline Pluralidade & $\begin{array}{l}\text { Promover o acesso à informação por meio da pluralidade de fontes de produção e dis- } \\
\text { tribuição do conteúdo. }\end{array}$ \\
\hline Imparcialidade & $\begin{array}{l}\text { Os jornalistas, comunicadores e todos aqueles que atuam no processamento da informação que } \\
\text { a EBC oferece ao público têm o dever de evitar o partidarismo, a pregação religiosa, o tom pro- } \\
\text { mocional e qualquer finalidade propagandística. A informação deve refletir a verdade dos fatos. }\end{array}$ \\
\hline Liberdade & Valorizar e defender a liberdade de imprensa e de expressão como fundamento da democracia; \\
\hline
\end{tabular}

5 Mensalão se refere a um escândalo político que aconteceu entre 2005 e 2006 durante a gestão do Governo Lula (PT). 0 esquema se caracterizou pela compra de votos de parlamentares do Congresso Nacional do Brasil para viabilizar a aprovação dos projetos encaminhados pelo governo federal. A investigação foi realizada pelo Ministério Público e o julgamento realizado pelo Supremo Tribunal Federal em 2014."

6 A Empresa Brasil de Comunicação (EBC) foi criada em 2007 com o intuito de gerir as emissoras de rádio e televisões públicas federais. Atualmente, é responsável pela TV Brasil, Rádios EBC, Agência Brasil, Radioagência Nacional e Portal EBC. 0 órgão conta com um Conselho Curador que tem 0 objetivo de fiscalizar a programação e constituir um elo entre a sociedade e as atividades desenvolvidas pela EBC. 


\begin{tabular}{|l|l|}
\hline Debate Público & $\begin{array}{l}\text { Fornecer espaços e meios para o debate público acerca de temas de relevância local, regional, na- } \\
\text { cional e internacional, assegurada a expressão de ideias, opiniões e pontos de vista divergentes. }\end{array}$ \\
\hline Proselitsmo & Vedar qualquer forma de proselitismo. \\
\hline Inovação & $\begin{array}{l}\text { Buscar excelência em conteúdos e linguagens e desenvolver formatos criativos e inova- } \\
\text { dores, constituindo-se em centro de inovação e formação de talentos. }\end{array}$ \\
\hline
\end{tabular}

Fonte: Manual de Jornalismo da EBC, 2013: 23-24

É importante compreender esses indicadores de qualidade pois também se constituem parâmetros de análise. Um tópico do manual intitula-se denúncias e denuncismo, estabelece que "toda denúncia deve ser confirmada antes de ser publicada" (Manual de Jornalismo da EBC: 2013: 31). A apuração é evidenciada de forma paralela à cautela no tratamento da informação.

É recorrente a busca da repercussão para uma denúncia visando a transformá-la em realidade ou gerar consequências concretas pela força da difusão. Os interesses por trás dessas denúncias são ocultos e o jornalismo da EBC tem a obrigação de esforçar-se para não ser instrumento desse tipo de ação, habitualmente rotulada como denuncismo (Manual de Jornalismo da EBC: 2013: 31).

0 órgão também evidencia a necessidade de informar o cidadão a respeito de cada acontecimento, inclusive o desfecho.

Muitos dos preceitos elencados pela EBC, que servem de norteadores qualitativos para o Repórter Brasil, também são considerados pelo Jornal Nacional, da TV Globo, como a isenção e a necessidade de levar a informação de forma completa e verídica ao telespectador. Os aspetos estão descritos nos Princípios Editoriais das Organizações Globo, publicizados em agosto de 2011. Um dos tópicos trata da necessidade de correção diante da veiculação de conteúdo equivocado; também estabelece-se a priorização do contraponto, de forma que todos os envolvidos em uma notícia sejam ouvidos. Segundo o editor chefe e apresentador do Jornal Nacional, William Bonner (2009) o principal objetivo do telejornal é noticiar o que de mais importante aconteceu no Brasil e no mundo. Se por um lado a expressão, pode ser interpretada como uma necessidade de manter o telespectador informado, ela também pode ser analisada, através de um olhar crítico, como uma preocupação do editor chefe em evitar furos jornalísticos e estar sempre à frente do que é divulgado pela mídia - aumentando assim a credibilidade perante a audiência e os anunciantes.

Em termos histórico-estruturais, o Jornal Nacional é telejornal mais antigo ainda em veiculação na televisão brasileira e consolida-se ano após ano como o de maior audiência. Veiculado na emissora de propriedade da família Marinho, a primeira edição foi exibida em 1969. Assim como Repórter Brasil também é transmitido no período noturno, porém, com início às 20h30. A duração é de pouco mais de 30 minutos.

\section{Parâmetros de análise da qualidade}

Na busca pela elaboração de indicadores que possam servir como parâmetros de análise do conteúdo do Jornal Nacional e do Repórter Brasil considera-se necessária uma revisão teórica que aborde os papéis das emissoras públicas e comerciais e indique critérios de qualidade voltados para a área audiovisual jornalística. 
Um dos trabalhos que é considerado referência para a radiofusão pública são os indicadores de qualidade formulados por Bucci et al. (2012) com parte da série Debates, da Organização das Nações Unidas para a Educação, a Ciência e a Cultura (UNESCO). Em um breve histórico, os autores resgatam a importância da independência para as emissoras públicas, já que "na prática, e não apenas na lei, a radiodifusão deve levar informação e cultura à sociedade, ajudando-a no acesso à informação independente, no livre trânsito das ideias e na formação crítica dos cidadãos (Bucci et al.: 2012: 13).

Os autores elaboraram 188 indicadores de qualidade, que na prática, são perguntas que devem auxiliar o comunicador e gestor da TV Pública a avaliar se 0 jornalismo praticado pela emissora cumpre seu papel em uma sociedade democrática. Os indicadores são formulados com base em três condições que Bucci et al. (2012) consideram essenciais para atender ao interesse público: a independência, garantia de financiamento e transparência.

$\mathrm{Na}$ formulação da base qualitativa, Bucci et al. (2012) utiliza como base 0 estudo de Eric Barendt, que cita aspectos que devem caracterizar uma TV Pública. Entre eles, destacam-se a abrangência geográfica, a preocupação com a identidade e a cultura nacionais, a independência tanto do Estado quanto de interesses comerciais, a imparcialidade e a diversidade na programação e financiamento substancial proveniente de uma taxa paga pelos usuários?.

Outra contribuição para pensar a qualidade é o conceito de modo de endereçamento, utilizado na análise do telejornalismo por Gomes (2005), que aborda as estratégias do Jornal Nacional para se identificar com o telespectador. "Modo de endereçamento é aquilo que é característico das formas e práticas comunicativas específicas de um programa, diz respeito ao modo como um programa específico tenta estabelecer uma forma particular de relação com sua audiência" (Morley \& Brunsdon: 1978, apud Gomes: 2005: 2). Segundo Gomes (2005) a compreensão do modo de endereçamento é feita através de operadores, que são definidos como os mediadores ; a temática e organização das editorias; o pacto sobre o papel do jornalismo; o contexto comunicativo; os recursos técnicos a serviço do jornalismo; os recursos da linguagem televisiva; os formatos de apresentação da notícia; a relação com as fontes de informação; e 0 texto verbal. A autora ainda cita uma série de elementos que faz com que o estilo do telejornal se identifique com a audiência, como a humanização dos relatos, os apresentadores, o sentimento nacionalista, entre tantos outros. Um dos exemplos se refere a imparcialidade. "A notícia "imparcial" e in loco é a marca privilegiada do JN. Uma das formas mais visíveis da construção da credibilidade no JN é através da elaboração, retórica, dos "dois lados da notícia"9 (Gomes: 2005: 8).

7 Algumas TVs Públicas que são consideradas referências, como a BBC, aplicam a taxa aos cidadãos, como diz Rothberg (2011). Entretanto, vários autores discutem a dificuldade de implantá-la em países onde não há a tradição dessa cobrança, como é o caso do Brasil. Portanto, os recursos são repassados de forma majoritária pelo Governo, que não exclui o caráter público da emissora, apesar da necessidade de avaliar sistematicamente a influência deste na programação da emissora.

8 Segundo Gomes (2005), os mediadores são caracterizados pelos apresentadores ou pivôs; a temática e a organização das editorias são descritos no telejornalismo como atenção concedida a forma de organizar e apresentar diferentes editorias, estabelecer uma proximidade com a audiência; o pacto sobre o papel do jornalismo trata da ligação entre o programa e o telespectador, referindo-se aos elementos que efetuam a relação entre ambos; e o contexto comunicativo é definido como 0 ambiente em que o programa televiso é veiculado.

9 Traquina (2005) faz uma crítica a respeito da forma como muitos telejornais constroem a nar- 
Também tratando da qualidade, Becker (2009), afirma que os cuidados básicos com as informações, como a apuração, são capazes de gerar uma notícia de qualidade. Porém, reforça que é preciso ir além. A questão da diversidade de programas e conteúdos destinados a diferentes audiências e a descentralização dos meios é colocada como um ponto essencial para o fortalecimento da democracia e para a qualidade do trabalho jornalístico (Becker: 2009: 107). A autora também aborda um dos pontos mais conflitantes que envolvem as emissoras em relação aos seus financiadores.

As relações das empresas de comunicação com os poderes públicos e privados limitam a construção de relatos jornalísticos, assim como as condições de produção, e os recursos financeiros disponíveis para serem investidos em matérias mais elaboradas. Não podemos compreender o jornalismo como uma atividade filantrópica, a notícia é um produto, mas há possibilidade de trabalhar os conteúdos jornalísticos, garantindo lucros, com notícias mais contextualizadas (Becker: 2009: 107).

Também podemos utilizar como critério de qualidade os preceitos que vem sendo elaborados por Coutinho (2014) na coordenação de pesquisas que envolvem o telejornalismo público, através do Laboratório de Jornalismo e Narrativas Audiovisuais. Em artigo publicado na quarta edição da Revista do Conselho Curador da EBC foi enfatizada como a ausência de uma regulação midiática no Brasil tem comprometido a prática de critérios que são constantemente levantados por organizações, pesquisadores e profissionais de comunicação - o que dificulta a formação de um papel midiático além da informação, com a propriedade de compreensão e reflexão da realidade.

A pesquisadora afirma que os pressupostos da TV Pública, como o pluralismo, diversidade e independência, devem também ser incorporados ao jornalismo em geral, o que concluímos ser independentemente de modelos de financiamento. Assim, a TV Pública brasileira pode ocupar um lugar importante, no sentido de aprimorar 0 interesse público e as diretrizes de atuação da mídia.

Em relação aos aspectos qualitativos que devem constar na grade da emissora, além dos citados anteriormente, Coutinho (2014) ainda considera o compromisso com a cidadania - que deve se traduzir na preocupação em explicitar os contextos e problemáticas e incentivar a participação de forma que crie o sentimento de protagonismo por parte do telespectador. Essas premissas constituiriam a base de uma TV que tem por objetivo criar um sentimento de pertencimento por parte dos cidadãos. A autora afirma que "essa nova forma de narrar, nos canais públicos da EBC, teria como diretrizes editoriais: cobertura temática, prestação de serviços, espaço para a prestação de serviços e protagonismo do cidadão (Coutinho: 2014: 28).

\section{Metodologia de análise}

A divulgação por parte da imprensa do depoimento de Paulo Roberto Costa, ex-diretor de abastecimento da Petrobrás, e do doleiro Alberto Youssef, é considerada o ponto de partida da análise. A primeira matéria a respeito do assunto foi

rativa. Essa estrutura comumente é veiculada através de dois lados, o bem contra o mal - numa analogia a velha dualidade moço versus vilão. 
veiculada no dia 09 de outubro pelo Jornal Nacional e um dia depois pelo Repórter Brasil. Entretanto, para a definição das edições de análise foi preciso considerar dois fatores. Primeiramente, o período de repercussão - já que era de se esperar que ambos os telejornais, de acordo com o que preveem o próprio manual de jornalismo e os princípios editoriais, iriam acompanhar o desenvolvimento do caso, e o período que compreendeu o segundo turno das eleições para presidente, que se estendeu dos dias 06 de outubro até 26 do mesmo mês.

Diante das variáveis, a análise foi realizada entre os dias 09 de outubro, data da divulgação dos depoimentos, até 25 de outubro, quando foram veiculadas as últimas edições do Jornal Nacional e Repórter Brasil antes das votações do segundo turno. 0 conteúdo foi capturado através do site $^{10}$ de cada noticiário, que disponibiliza as matérias poucas horas depois de serem veiculadas na TV aberta.

No total foram 15 edições analisadas do Jornal Nacional e 14 do Repórter Brasil. A diferença quantitativa se refere à ausência da edição do dia 09 de outubro por parte do Repórter Brasil. Um e-mail chegou a ser enviado para a diretoria de jornalismo da EBC que confirmou que os vídeos não foram carregados para a página virtual. Entretanto, por dedução, consideramos que provavelmente a primeira inserção sobre 0 assunto foi divulgada apenas no dia 10, já que nesta data 0 título do vídeo foi definido como "Justiça Federal divulga depoimento do ex-diretor de abastecimento da Petrobrás", entendendo-se, portanto, que foi a partir deste momento que o Repórter Brasil iniciou a cobertura referente aos depoimentos de Paulo Roberto Costa - o que não prejudicaria este estudo.

A metodologia utilizada, de análise de conteúdo, considerou os seguintes aspectos:

1. Formato: no que se refere a classificação da estrutura da reportagem, como por exemplo, nota seca, nota coberta, reportagem completa ${ }^{11}$, stand-up ${ }^{12}$ ou vivo $0^{13}$.

2. Sonoras: além da quantidade também buscamos identificar o posicionamento político de cada pessoa entrevistada, e perceber aspectos relativos à isenção e pluralidade.

3. Tempo: em cada inserção foi medido o tempo de duração. 0 tempo dedicado ao assunto é um dado que permite visualizar situações de omissão ou

100 acesso aos sites é aberto. A página do Jornal Nacional está disponível no Portal G1, através do link: g1.globo.com/jornal-nacional. Já as edições Repórter Brasil podem ser acessadas através do link: tvbrasil.ebc.com.br/reporterbrasil.

11 Neste trabalho utiliza-se como conceito de reportagem completa o modelo mais difundido pelas TVs comerciais e públicas brasileiras, composto por off-sonora-passagem. 0 primeiro se refere a locução do repórter sobre as imagens; a sonora são as entrevistas; a passagem representa a aparência do repórter, geralmente com a função de acrescentar uma nova informação ou direcionar a reportagem para outra angulação.

12 Stand-up é um modelo de veiculação da notícia semelhante ao vivo, entretanto, se diferencia por ser gravado. Nele, o repórter grava as informações olhando diretamente para a câmera, com ou sem a presença de um entrevistado.

130 vivo consiste na participação do repórter no telejornal em tempo real. A inserção é feita após a cabeça do apresentador. 0 vivo tem o costume de ser realizado no local do acontecimento, de forma à caracterizar o assunto em questão. É utilizado para dar dinâmica ao noticiário com informações de última hora ou que ainda estão acontecendo. 
excessos na cobertura. Na análise, consideramos no tempo total, além do $V^{14}$, a cabeça ${ }^{15}$ e a nota pé16.

4. Recursos: este tópico se refere aos recursos utilizados pela equipe de reportagem e pela edição para tornar o formato utilizado mais rico, seja em forma de artes, narrativas diferenciadas ou uso de arquivos.

Por meio destes operadores buscou-se levantar dados qualitativos e quantitativos, de forma que pudessem indicar caminhos interpretativos que permitam visualizar as características de cada cobertura, os pontos fortes e fracos e as contribuições para um telejornalismo de qualidade.

\section{Petrobrás em pauta: análise das coberturas}

A primeira divulgação dos depoimentos de Costa e Youssef pelo Jornal Nacional foi realizada no dia 09 de outubro - um dia antes do Repórter Brasil. A reportagem teve duração extensa para o padrão do telejornal cujas matérias raramente passam dos 3 minutos. Com 7 minutos e 48 segundos, mais 1 minuto e 39 segundos de nota pé, a reportagem intitulada "Ex-diretor da Petrobrás e doleiro Alberto Youssef delatam a corrupção da Petrobrás" divulgou vários trechos dos depoimentos dos réus do caso Petrolão. Neles, foi explicado como eram realizados os desvios, os beneficiados e a porcentagem de recursos destinada aos corruptores.

A matéria utiliza imagens do local onde aconteceram os depoimentos, fachadas de prédios, como do Supremo Tribunal Federal, imagens de arquivo para mostrar os dois envolvidos (enquanto cita em off partes dos depoimentos), arte para explicar como funcionava o esquema que envolvia três partidos (PP, PMDB e PT) e para detalhar 0 áudio dos depoimentos. Em síntese, explica que a propina era viabilizada através de um desvio de um percentual dos contratos realizados com as empreiteiras que era repassado a membros internos da Petrobrás e encaminhado também a políticos.

Deve-se notar que apesar da reportagem ser longa, não houve nenhuma entrevista. Essa constatação pode entrar em choque com os preceitos de qualidade defendidos pelos princípios editoriais da emissora. Em uma inserção com mais de 10 minutos, incluindo cabeças e notas pé, a ausência de entrevistas também pode ser interpretada como uma estrutura incapaz de gerar contrapontos,

14 VT é todo o conteúdo audiovisual editado pela ilha de edição de um telejornal. Podem ser reportagens, matérias, stand-up ou mesmo um infográfico previamente gravado. Os VTs são organizados antes do telejornal começar através de um espelho - onde consta todos os VTs que deverão ser veiculados pelo noticiário.

15 Cabeça é o texto lido pelo apresentador que antecede a reportagem. Tem o objetivo de contextualizar o telespectador acerca da matéria que será exibida em seguida.

16 Nota pé se refere ao texto lido pelos apresentadores após a exibição de uma reportagem. Tem a função de complementar a matéria com informações que não foram inseridas no texto do repórter. No Brasil, em reportagens de denúncia, é comum inserir na nota pé a versão dos envolvidos que não ganharam espaço através de entrevista no VT. 
já que a única versão apresentada é relativa a organização da matéria - realizada pelos próprios editores. Especialistas políticos, os próprios envolvidos e representantes dos partidos não foram ouvidos. 0 espaço foi concedido apenas em nota pé, lidas, como de prática, pelos próprios editores-apresentadores do Jornal Nacional.

Também é questionável o critério escolhido para o uso das imagens de arquivo dos personagens para cobrir o off da repórter que detalha os depoimentos. Em uma delas, visivelmente antiga e aparentemente incompatível com 0 "padrão Globo de qualidade ${ }^{7 "}$, aparece Youssef (aparentemente mais novo que atualmente) em uma mesa piscando um dos olhos - numa simbologia que remete à esperteza ou atos dignos de entrelinhas. A escolha da imagem pode ter sido estratégica pelos editores do telejornal para "encaixar" o personagem a imagem de corrupto.

Figura 1: Youssef representado pelas imagens de arquivo do Jornal Nacional
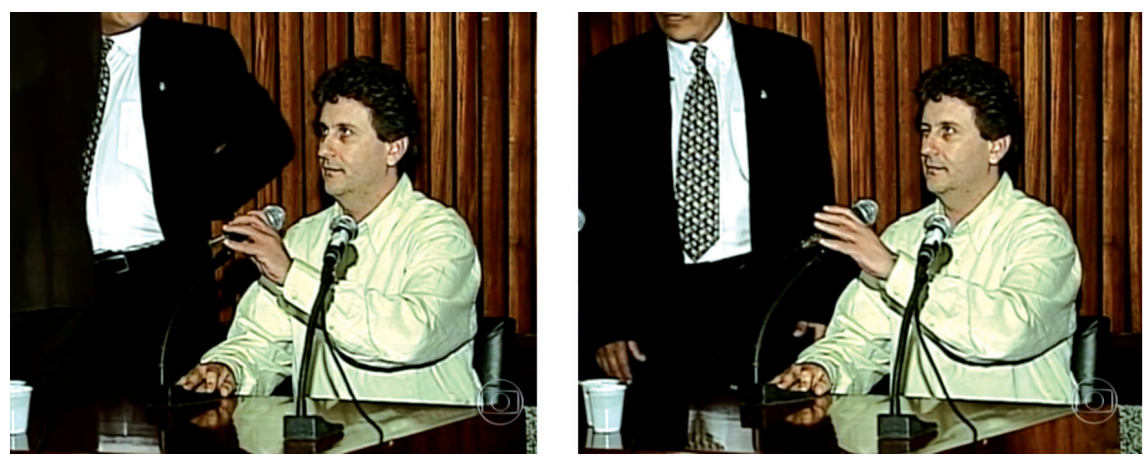

Legenda: As imagens capturadas na página do Jornal Nacional na internet mostram sequência de frames do arquivo veiculado pelo telejornal para cobrir o off da repórter quando se cita o doleiro Alberto Youssef.

Nos dois dias seguintes, o telejornal exibiu matérias que repercutiram o caso. Duas delas, inclusive, apresentaram conteúdo semelhantes. Através do próprio título é possível visualizar essa aproximação de propostas. No dia 10/10/2014 foi veiculada "Ex-diretor da Petrobrás e doleiro dão detalhes sobre cartel e corrupção e contratos". Já a do dia 11/10/2014 traz como título "Paulo Roberto Costa revela detalhes de como os operadores atuavam para garantir propinas". A impressão ao realizar a análise de conteúdo é de que o telejornal buscou divulgar as informações dos depoimentos em pequenos pacotes, de forma que tivesse conteúdo "inédito" por vários dias. A inovação também não aparece na estrutura das duas reportagens, que assim como a veiculada no dia 09 de outubro, não fazem uso de sonoras e se utilizam dos depoimentos divulgados pela justiça através de artes.

Nestes três dias, a única reportagem que se distanciou deste padrão foi a exibida no dia 10/10/2014 que mostrou como os depoimentos de Costa e Youssef estavam se refletindo nas campanhas eleitorais. 0 candidato à presidência Aécio Neves (PSDB), da oposição, afirmou em sonora de 39 segundos que a cor- 
rupção se institucionalizou no que chama de "seio da nossa maior empresa" e cobra maior investigação, prometendo, caso fosse eleito, que iria aprofundá-las. Já a candidata à reeleição do PT, Dilma Rousseff, disse em sonora cinco segundos maior, estranhar a divulgação dos áudios em meio a campanha eleitoral e defendeu a apuração do caso. Na própria reportagem e na nota pé, o telejornal rebateu, de forma discreta, a fala da presidente, ressaltando que os depoimentos não eram sigilosos.

Ainda neste contexto, percebe-se que o Jornal Nacional buscou resguardar sua credibilidade acerca da acusação de Dilma Rousseff a respeito da divulgação dos depoimentos em pleno segundo turno eleitoral. No dia 14/10/2014, a matéria "Juízes federais apoiam colega responsável pela apuração do escândalo da Petrobras" mostra que a Associação dos Juízes Federais do Brasil, a oposição e o Ministério Público do Paraná defenderam a atuação do Juiz Sérgio Moro, que autorizou a divulgação do conteúdo do depoimento de Costa e Youssef. Em sonora, o vice-presidente da associação dos juízes explica que a investigação é pública, por isso, não houve irregularidade. Entretanto nota-se a ausência do principal personagem de toda a reportagem. 0 Juiz Sérgio Moro, mote da matéria, não foi ouvido e os apresentadores e o repórter também não falaram se tentaram entrar em contato com ele. Questiona-se, neste caso, o motivo dessa opção. Várias perguntas, que deveriam ser feitas ao juiz ficaram sem respostas - entre elas, o porquê de não ser sigiloso? os depoimentos, que não foram comprovados ainda e estão em investigação, não poderiam beneficiar determinado candidato em pleno segundo turno eleitoral?

No dia 15/10/2014 o Jornal Nacional repercutiu o assunto dizendo que outra obra da Petrobrás estava sendo investigada. Em nenhum momento é dito se as denúncias foram ou não confirmadas - situação que ganha peso considerando o período eleitoral. Na única sonora da reportagem de 2 minutos e 11 segundos, um relator do Tribunal de Contas da União (TCU) diz que a denúncia é grave, mas que precisa ser investigada. Apesar de citado como um dos comandantes do esquema, Costa não foi ouvido.

Em meio às polêmicas, direcionadas principalmente a aliados do governo, na edição de 17/10/2014 0 Jornal Nacional exibiu uma reportagem de 4 minutos e 29 segundos dizendo que Costa citou um membro da oposição (PSDB) como um dos políticos que recebeu propina. 0 telejornal utiliza de imagens dos jornais impressos Folha de São Paulo e Estado de São Paulo para desenvolver o assunto. Considerando o tempo midiático de cada veículo, questiona-se o fato do telejornal, que deveria ter mais agilidade para informar, ter sido pautado pelos impressos. A matéria diz que cerca de $R \$ 10$ milhões teriam sido desviados para abastecer a campanha do PSDB - partido de Aécio Neves - em 2010. Apontado como possível operador, o senador Álvaro Dias (PSDB), foi ouvido em sonora e negou a participação. No mesmo VT é dito que um órgão americano que cuida do mercado de ações também investiga a Petrobrás. São utilizadas imagens de relatórios e da fachada do Departamento de Justiça dos Estados Unidos.

Durante o período analisado, o Jornal Nacional fez 0 uso de 9 sonoras. A distribuição dos posicionamentos políticos ficou configurado da seguinte forma, segundo a análise: 


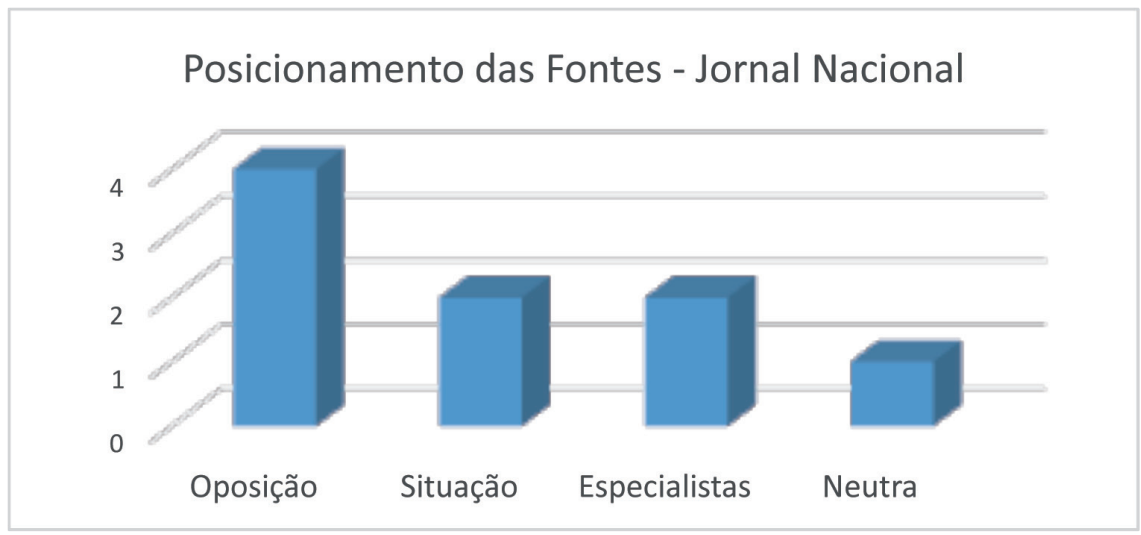

Entre os que foram enquadrados como oposição, estão o líder do PSDB que cobrou investigação; o senador Álvaro Dias (PSDB), que se defendeu da acusação de ser considerado um dos operadores do esquema; e o candidato à presidência Aécio Neves. Visualizados como da situação, estão a candidata à reeleição Dilma Rousseff e o relator da CPMI, Marcos Maia (PT) que concedeu uma entrevista dizendo que não poderia levar as denúncias para 0 lado eleitoral. Foram classificados como especialistas o membro da Associação dos Juízes Federais do Brasil, que defendeu a atuação do juiz Sérgio Moro em relação a divulgação dos depoimentos, e o relator do TCU, Ministro José Jorge, ao falar da apuração de mais uma obra vista como superfaturada por funcionários da Petrobrás. Incluído na categoria de sonora neutra, 0 presidente da CPMI, Vital do Rêgo (PMDB), é ouvido na condição de presidente da comissão de investigação - apesar de pertencer a um partido da base aliada do governo.

Já o Repórter Brasil apresentou uma cobertura bastante distinta da realizada pelo Jornal Nacional. Nos 15 dias dedicados à análise, em apenas quatro o tema esteve presente no script do noticiário - mesmo assim, na maioria das vezes, em formato de nota seca. Apenas no primeiro dia foi inserida uma arte com um trecho do depoimento do ex-diretor de abastecimento da Petrobrás, Paulo Roberto Costa. Portanto, a configuração do formato da notícia se distanciou do que se viu na emissora comercial. 


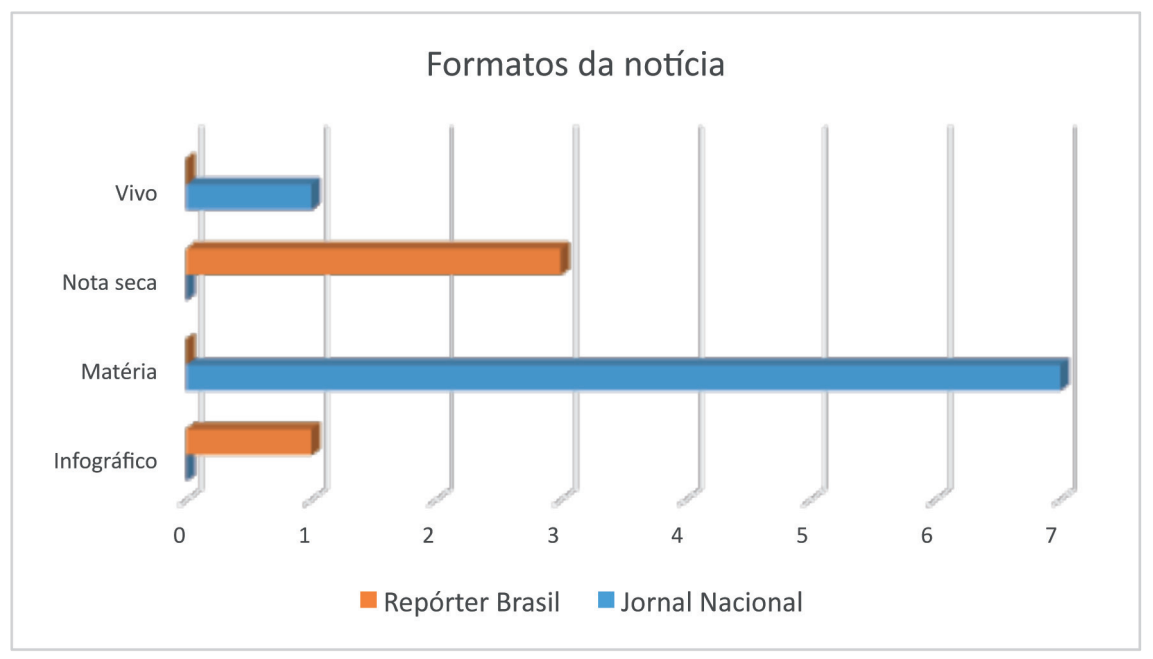

Fontes: Jornal Nacional e Repórter Brasil $2^{a}$ Edição

A opção pelo uso predominante de notas secas contrapõe com o Manual de Jornalismo da EBC - que dita as normais editorais da TV Brasil. Esse formato pode ser considerado pobre em termos de recursos jornalísticos que poderiam fomentar o debate público e o contraponto de ideias, já que não há sonoras, imagens e as informações que um VT poderia oferecer ao telespectador.

Com 2 minutos e 27 segundos, a inserção do dia 10/10/2014 foi a maior, considerando o período analisado. Com o título "Justiça Federal divulga depoimento do ex-diretor de abastecimento da Petrobras", os apresentadores destacaram na cabeça o histórico de Paulo Roberto Costa na Petrobrás, sendo funcionário de carreira por décadas - o que não foi dito no Jornal Nacional. É citado que ele foi indicado por um ex-deputado do PP a diretoria de abastecimento em 2004. Em nenhum momento é mencionada a palavra Lula ou Dilma, ao contrário do que aconteceu no telejornal da TV Globo. Os apresentadores também dizem que o Ministério Público ainda vai investigar as informações divulgadas por Costa. Depois da cabeça de 1 minuto e 24 segundos é inserido 0 áudio de Costa detalhando como acontecia o esquema. 0 outro lado é dado através de nota pé. As outras três inserções sobre o assunto foram feitas através de notas secas, como demonstra o Quadro 2: 
Quadro 2: As notas secas veiculas pelo Repórter Brasil

\begin{tabular}{|c|c|c|l|}
\hline Data & Título & Tempo & \multicolumn{1}{c|}{ Conteúdo da Nota Seca } \\
\hline $15 / 10$ & $\begin{array}{l}\text { Presidente da CPI Mista } \\
\text { da Petrobras entra com } \\
\text { mandato de segurança }\end{array}$ & $0: 21$ & $\begin{array}{l}\text { Notícia que o senador Vital do Rego, presidente } \\
\text { da CPMI da Petrobrás, pediu no Supremo Tribu- } \\
\text { nal Federal o depoimento de Costa prestado em } \\
\text { regime de delação premiada. No Jornal Nacional } \\
\text { a informação foi dada na passagem da repórter } \\
\text { em um VT que mostra possíveis irregularidades } \\
\text { em uma obra da Petrobrás, no Rio de Janeiro. }\end{array}$ \\
\hline $21 / 10$ & $\begin{array}{c}\text { Justiça Federal do } \\
\text { Paraná absolve doleiro } \\
\text { Alberto Youssef. }\end{array}$ & $00: 24$ & $\begin{array}{l}\text { Fala da absolvição de Youssef da acusação de } \\
\text { lavagem de dinheiro do tráfico de drogas. Também é } \\
\text { citado que ele é investigado na Operação Lava Jato. }\end{array}$ \\
\hline $22 / 10$ & $\begin{array}{l}\text { Justiça Federal de Cu- } \\
\text { ritiba condena doleira } \\
\text { Nelma Kodama a 18 } \\
\text { anos de prisão. }\end{array}$ & $0: 31$ & $\begin{array}{l}\text { Trata da condenação da doleira Nelma Kodama, } \\
\text { que teria atuado junto com Youssef na lavagem } \\
\text { de dinheiro. A ação faz parte da Operação Lava } \\
\text { Jato. O Repórter Brasil explica como a doleira } \\
\text { atuava: por meio de empresas fantasmas para } \\
\text { abastecer os negócios de Youssef. }\end{array}$ \\
\hline
\end{tabular}

Fonte: Repórter Brasil $2^{\mathrm{a}}$ Edição

Ao traçar um paralelo com o Jornal Nacional, nota-se algumas diferenças no tratamento da informação. Na nota seca divulgada no dia 21/10/2014 sobre a absolvição de Youssef, por exemplo, a apresentadora do Repórter Brasil explica a justificativa dada pelo juiz, de que o doleiro emprestou o escritório sem saber que o local seria usado para tratar de assuntos relacionados ao tráfico. No Jornal Nacional é dito somente o motivo dele ser acusado, em relação ao envolvimento com traficantes colombianos - percebe-se um lado mais acusador, pouco preocupado com as justificativas da absolvição, ou com o lado de quem o telejornal considera como sendo 0 "mal". Já no dia seguinte, diante da condenação de Nelma Kodama, o Repórter Brasil já utiliza um tom mais próximo do Jornal Nacional ao explicar a ação da doleira.

Diante das coberturas analisadas, nota-se um grande distanciamento em relação ao tempo gasto por cada telejornal.

\section{Gráfico 3}

Tempo de cobertura

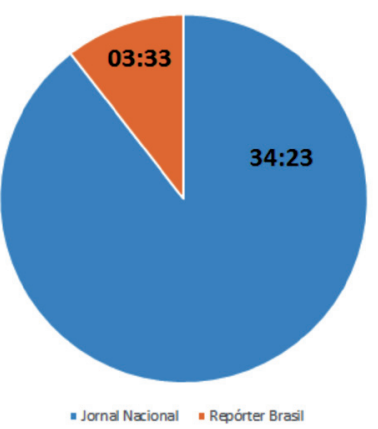

Fontes: Jornal Nacional e Repórter Brasil 2ª Edição 
0 Repórter Brasil gastou 1/10 do tempo dedicado pelo Jornal Nacional aos assuntos relacionados a divulgação dos depoimentos de Costa e Youssef. Além do tema aparecer menos ao longo das edições, as notas secas foram lidas de forma breve, com média de 21 a 31 segundos cada. Já o Jornal Nacional gastou mais tempo com matérias longas, que também incluíram o uso de artes e imagens gravadas no exterior.

\section{Consideracõ̃es finais}

É dedutível que o tempo reduzido dedicado pelo Repórter Brasil ao tema é passível de questionamentos, principalmente acerca se 0 assunto não deveria ser tratado como pertencente ao interesse público. A Petrobrás é uma empresa brasileira, cuja maioria das ações pertence ao Estado. Portanto, a população saber o que acontece dentro dela pode ser considerado de interesse público - já que a mídia também deve exercer um papel fiscalizador. Entretanto, há um agravante que é 0 segundo turno da eleição para presidente, caracterizado por uma disputa acirrada, onde em várias pesquisas 0 atual governo, candidato à reeleição, aparecia atrás do candidato da oposição por poucos pontos percentuais. Se por um lado demonstra a necessidade de tratar o tema com cautela e responsabilidade jornalística, também é um motivo para que o governo tente conter qualquer divulgação que possa se refletir na votação.

Considerando este cenário e os dados apresentados, conclui-se, ao relacionar os resultados desta pesquisa com os obtidos pela análise do caso Pasadena, que a conduta de "retração" está incorporada a linha editorial da emissora pública (TV Brasil). Na análise realizada em março, o Repórter Brasil dedicou 3 minutos e 20 segundos, enquanto o Jornal Nacional gastou 54 minutos e 41 segundos nos mesmos dias analisados. Aparenta-se que o Repórter Brasil insere 0 assunto na grade do telejornal apenas por uma obrigação como veículo informativo - já que não há aprofundamentos e a ausência total do assunto poderia evidenciar ainda mais sua dependência do governo federal.

0 Repórter Brasil é gravado em Brasília, na mesma cidade onde transmita a CPMI que investiga o caso. Em nenhum momento uma equipe de reportagem foi ao local para mostrar a movimentação do Congresso Nacional e ouvir os partidos envolvidos. Portanto, não se pode justificar a ausência do assunto às questões de falta de infraestrutura. Por outro lado, percebe-se 0 empenho e o poderio do noticiário da TV Comercial, que com maiores recursos financeiros e tecnológicos, conseguiu mostrar a repercussão da crise da Petrobrás no exterior, com imagens gravadas nos Estados Unidos.

Devido a fatores, como os provenientes de posicionamentos políticos e da própria complexidade no tratamento da informação, é difícil compreender a linha que separa a omissão, que poderia ser atribuída ao Repórter Brasil, e do exagero, que muitos poderiam vincular ao Jornal Nacional. A cobertura do caso e esses questionamentos devem ser vistos não apenas como críticas a cada um dos noticiários, mas também como a necessidade de discutir como cenários semelhantes devem ser tratados pela mídia que prima pela qualidade.

Acreditamos que a notícia quando é fruto de um processo que ainda está em investigação não deve ser tratada como uma verdade. Apesar do Jornal Nacional repetir em todas as matérias a expressão "segundo o depoimento", a massificação do tema durante as edições ao longo do segundo turno pode levar o telespectador/eleitor 
a processar a denúncia como sendo uma verdade. Foram 34 minutos e 23 segundos de informações que ainda não foram confirmadas - e que estão sendo investigadas.

Portanto, os depoimentos que estão em fase de investigação, em nenhum momento ganharam repercussão aprofundada de que poderiam ser considerados falsos. Esta perspectiva só era apresentada pelas notas pé, em poucos segundos, no breve direito de defesa de alguma pessoa ou algum órgão citado pelos réus. Podemos utilizar numa perspectiva de ilustração para melhor compreensão, uma conduta frequente de alguns telejornais. Em coberturas de homicídios, tráficos e roubos, muitas vezes evita-se veicular a sonora do acusado - a justificativa nas redações é feita através de uma velha pergunta: porque dar voz a bandido? Diante deste raciocínio, questiona-se então o fato das pessoas que assumiram atos de corrupção, como Costa e Youssef, ganharem tanta voz - e consequentemente uma aparente credibilidade - na grande mídia comercial.

Em contraponto, acreditamos que uma forma alternativa de tratar o assunto numa perspectiva diferenciada é através de profissionais especializados em política, como cientistas políticos, que poderiam abordar 0 assunto de uma maneira mais profissional. Ausentes em ambos os telejornais, poderiam esclarecer o caso com melhor didatismo aos telespectadores - como o que representa os depoimentos, quem são os envolvidos, como a divulgação interfere nas eleições, entre outras perspectivas.

A emissora pública, que possui um compromisso com o cidadão que custeia sua programação, e a emissora comercial, cujo compromisso não é menor, por se tratar de uma concessão pública, deveriam seguir com maior fidelidade os princípios que descrevem de forma louvável em seus manuais e diretrizes editoriais - mas que muitas vezes, não são vistos na tela da TV. Promoção do debate de ideias, pluralidade, incentivo à reflexão e novas formas de abordar a notícia deveriam ser vistos em qualquer tipo de cobertura, independentemente da temática.

\section{Bibliografia}

Barbero, J. (2002). Televisão pública, televisão cultural: entre a renovaçã̃o e a invenção. In: Rincón, 0. (org.). Televisão pública: do consumidor ao cidadão(pp.41-80). São Paulo: ILDEs/FES. Becker, B. (2005). Telejornalismo de qualidade: um conceito em construção. Revista Galáxia 10: $51-64$.

Bonner, W. (2009). Jornal Nacional: Modo de Fazer. Rio de Janeiro: Globo.

Bucci, E., Fiorini, A.M. \& Chiaretti, M. (2012). Indicadores de Qualidade nas Emissoras Públicas - Uma Avaliação Contemporânea. Brasília: Unesco.

Cannito, N. (2010). A televisão na era digital: interatividade, convergência e novos modelos de negócio. São Paulo: Summus.

Coutinho, I (2008). Lógicas de uso do telejornal. Eco-pós 11: 61-79. (http://revistas.ufrj.br/ index.php/eco_pos/issue/view/130/showToc) (acedido 13/12/2014).

Coutinho, I. (2013). A informação na TV pública. Florianópolis: Insular.

Coutinho, I. (2014). 0 jornalismo público como parâmetro regulador do audiovisual. Revista do Conselho Curador 4: 26-28.

Fernández, V. (2002). Por uma televisão pública para a América Latina. In: Rincón, 0. (org.). Televisão pública: do consumidor ao cidadão (pp. 155-200). São Paulo: ILDEs/FES.

Freitas, A. J. de (2000). Jornalismo e Política no Brasil: Olhares contemporâneos. Anais do XXIII 
Congresso Brasileiro de Ciências da Comunicação. Manaus: Intercom. (http://www.portcom.intercom.org.br/pdfs/f1f783f2f480fe3dc9bc84e5de207929.pdf) (acedido 09/01/2015).

Gomes, I.M. (2005). Modo de endereçamento no telejornalismo do horário nobre brasileiro: o Jornal Nacional da Rede Globo de Televisão. Anais do XXVIII Congresso Brasileiro de Ciências da Comunicação. Intercom: Rio de Janeiro (Brasil), (CD`Rom).

Oliveira Filho, J.T. \& Coutinho, I. (2014). Entre denúncias e silêncios: a cobertura do caso Pasadena em emissoras de TV comercial e pública. Anais do XII Congresso Latino-americano dos Investigadores da Comunicação. Lima (Peru), 07-08 agosto

Princípios editoriais das Organizações Globo (http://g1.globo.com/principios-editoriais-das-organizacoes-globo.pdf) (acedido 23/12/2014).

Rothberg, D. (2011). Jornalismo público: informação, cidadania e televisão. São Paulo: Unesp.

Somente a verdade - Manual de Jornalismo da EBC (http://www.ebc.com.br/sites/default/ files/manual_de_jornalismo_ebc.pdf) (acedido 16/01/2015).

Telles, H., Fraiha, P.S. \& Lopes, N. Meios de Comunicação, corrupção e redes sociais nas eleições para prefeito no Brasil (2014). In: Cunha, I. F. \& Serrano, E. (coords.). Cobertura Jornalística da Corrupção Política (pp. 421-457). Lisboa: Alêtheia.

Traquina, N. (2004). Teorias do Jornalismo Volume I - Porque as notícias são como são. Florianópolis: Insular.

Traquina, N. (2005). Teorias do Jornalismo Volume II - A tribo jornalística, uma comunidade interpretativa transnacional. Florianópolis: Insular.

Vizeu, A. \& Correia, J.C. (2008). A construção do real no telejornalismo: do lugar de segurança ao lugar de referência. In: Vizeu, A. (org.). A sociedade do telejornalismo. Petrópolis: Vozes. 